\title{
Prevalence of Obesity in Hail Region, KSA: In a Comprehensive Survey
}

\author{
Hussain Gadelkarim Ahmed, ${ }^{1,2}$ Ibrahim Abdelmajeed Ginawi, ${ }^{1}$ \\ Abdelbaset Mohamed Elasbali, ${ }^{2,3}$ Ibraheem M. Ashankyty, ${ }^{2,3,4}$ and Awdah M. Al-hazimi ${ }^{1,5}$ \\ ${ }^{1}$ College of Medicine, University of Hail, Hail 2440, Saudi Arabia \\ ${ }^{2}$ Molecular Diagnostics and Personalised Therapeutics Unit, University of Hail, Saudi Arabia \\ ${ }^{3}$ College of Applied Medical Sciences, University of Hail, Hail, Saudi Arabia \\ ${ }^{4}$ College of Applied Medical Sciences, King Abdulaziz University, Jeddah, Saudi Arabia \\ ${ }^{5}$ College of Medicine, King Abdulaziz University, Jeddah, Saudi Arabia
}

Correspondence should be addressed to Hussain Gadelkarim Ahmed; hussaingad1972@yahoo.com

Received 5 April 2014; Revised 20 May 2014; Accepted 22 May 2014; Published 25 June 2014

Academic Editor: R. Prager

Copyright (C) 2014 Hussain Gadelkarim Ahmed et al. This is an open access article distributed under the Creative Commons Attribution License, which permits unrestricted use, distribution, and reproduction in any medium, provided the original work is properly cited.

Background. Obesity contributes significantly to morbidity and mortality rates worldwide. We, therefore, aimed to provide epidemiological data on the prevalence of obesity in Hail, Kingdom of Saudi Arabia (KSA). Methodology. Data were collected during cross-sectional survey which included 5000 Saudi selected from 30 primary health care centers (PHCs) in Hail Region. Results. The overall prevalence of obesity in Hail was $63.6 \%$. Moreover, the prevalence of males was $56.2 \%$ and the prevalence of females was $71 \%$. Conclusion. Obesity is prevalent in the Hail Region which necessitates urgent interventions including health education.

\section{Introduction}

Overweight and obesity are defined as abnormal or excessive fat accumulation that may impair health. Obesity represents a rapidly growing threat to the health of populations in an increasing number of countries. Overweight and obesity are the fifth leading risk for global deaths. At least 2.8 million adults die each year as a result of being overweight or obese. In addition, $44 \%$ of the diabetes burden, $23 \%$ of the ischaemic heart disease burden, and between $7 \%$ and $41 \%$ of certain cancer burdens are attributable to overweight and obesity [1]. Obesity comorbidities include coronary heart disease, hypertension and stroke, certain types of cancer, noninsulin-dependent diabetes mellitus, gallbladder disease, dyslipidemia, osteoarthritis and gout, and pulmonary diseases, including sleep apnoea [2].

The move towards high-energy diet and an inactive life style has turned obesity from a developed-world event into a global epidemic [3-5]. Obesity prevalence rates, as well as food intake habits, vary by demographic and socioeconomic groups [6-9]. In 2008, the WHO estimated that at least 500 million adults (greater than 10\%) are obese, with higher rates among women than men and more than 1.4 billion adults, 20 and older, were overweight [10]. Of the 500 million over weights, over 200 million men and nearly 300 million women were obese. About 35\% of adults aged 20 and over were overweight, and $11 \%$ were obese. About $65 \%$ of the world's population lives in countries where overweight and obesity kills more people than underweight. More than 40 million children under the age of five were overweight in 2011 [1].

Obesity is preventable. At an individual level, a combination of excessive food energy intake and a lack of physical activity are thought to explain most cases of obesity [11]. A limited number of cases are due primarily to genetics, medical reasons, or psychiatric illness $[12,13]$. In contrast, increasing rates of obesity at a societal level are felt to be due to an easily 
TABLE 1: Distribution of the study population by diabetes and age.

\begin{tabular}{lcccc}
\hline Age & Over wt & Obese & Morbid obesity & Total \\
\hline$<25$ years & 264 & 49 & 53 & 366 \\
$26-40$ & 387 & 185 & 119 & 691 \\
$41-55$ & 379 & 191 & 149 & 719 \\
$56-70$ & 287 & 117 & 73 & 477 \\
$71+$ & 120 & 47 & 32 & 199 \\
Total & $\mathbf{1 4 3 7}$ & $\mathbf{5 8 9}$ & $\mathbf{4 2 6}$ & $\mathbf{2 4 5 2}$ \\
\hline
\end{tabular}

accessible and palatable diet [14], increased reliance on cars, and mechanized manufacturing $[15,16]$.

KSA is one of the fastest growing economies of the world. The growth and prosperity, however, have brought marked changes in the lifestyle of people. Most eating habits are less healthful and the level of physical activity is very low. Accordingly, obesity is increasing in KSA at an alarming rate. Therefore, the purpose of this study was to assess the burden of the problem in Hail region, KSA.

\section{Materials and Methods}

Data regarding obesity were collected as a part of a comprehensive survey that included 5000 Saudi civilians living in Hail region Northern Saudi Arabia, during the period from October 2012 to December 2013. The sample size was calculated to obtain confidence level of $95 \%$ and confidence interval of 1.38. Participants were selected from 30/105 primary health care (PHC) centers by simple random method. The primary care program in Saudi Arabia is a leading program in the developing countries that has accomplished respectable success within a few years of its establishment. The Ministry of Health $(\mathrm{MOH})$ provides PHC services throughout Hail region comprising 105 centers. Participants were recruited to the local PHC in each area before one week of the campaign. On campaign day, all responding individuals were included up to the target of 5000 participants. The purpose of the survey was to estimate the prevalence of chronic kidney disease in the area. Data were collected by the doctors of the team utilizing a standard questionnaire, which included demographic information and previously diagnosed diseases (hypertension, diabetes, and others).

Diagnosis of hypertension was based on observation of blood pressure levels $>140 / 90 \mathrm{mmHg}$. Diagnosis of diabetes in this survey was based on the information provided by the participant of being under treatment for diabetes due to a previous well-established diagnosis then confirmed with new blood glucose estimation.

BMI was calculated from measured height and weight and classified as normal weight $\left(<25 \mathrm{~kg} / \mathrm{m}^{2}\right)$; overweight $\left(25-30 \mathrm{~kg} / \mathrm{m}^{2}\right)$; and obese $\left(30-35 \mathrm{~kg} / \mathrm{m}^{2}\right)$, morbid obesity $\left(>36 \mathrm{~kg} / \mathrm{m}^{2}\right)[17]$.

2.1. Statistical Analysis. Data management was done using Statistical Package for Social Sciences (SPSS version 16). SPSS was used for analysis and to perform the Pearson Chi-square

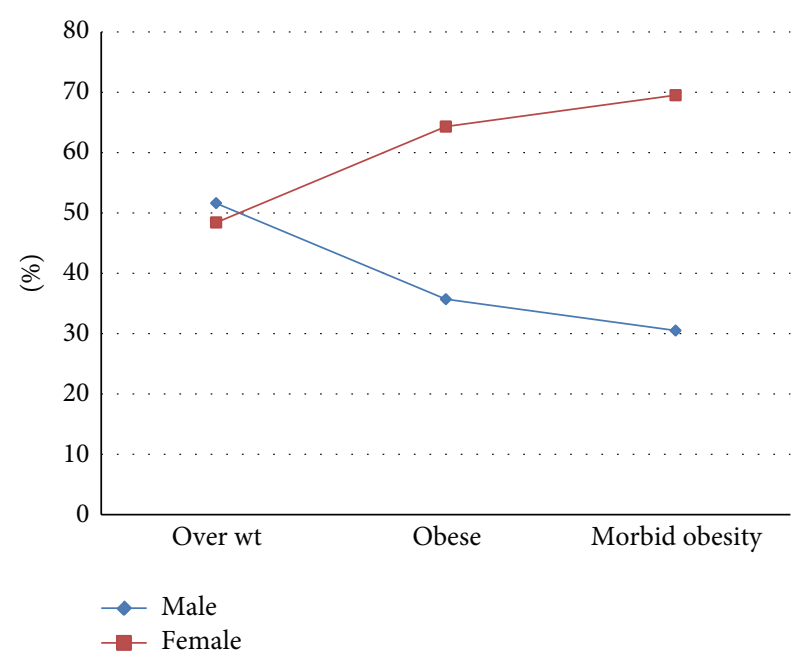

FIGURE 1: Description of BMI categories by gender.

test for statistical significance $(P$ value $<0.05)$. The $95 \%$ confidence level and confidence intervals were used.

\section{Results}

The mean age of the study population was $43.5 \pm 18.7$ years with $44.6 \pm 20.2$ for males and $42.3 \pm 16.9$ for females. Males to females ratio was $1.00: 1.01$. The overall prevalence of obesity in Hail was $63.6 \%$. Moreover, the prevalence of males was $56.2 \%$ and the prevalence of females was $71 \%$. When categorizing obesity, $37.3 \%, 15.3 \%$, and $11 \%$ were categorized as overweight, obese, and with morbid obesity, respectively. Moreover, increased weight categories were strongly linked to females and this was found to be statistically significant $(P<0.0001)$, as indicated in Figure 1.

Table 1 and Figure 1 summarizes the relationship between obesity and age. However, the peaks for all obesity categories were at middle age $41-55$ years $(P<0.05)$, followed by age range $26-40$ years, as indicated in Figure 2.

Furthermore, of the 2452 obese persons, 746/2452 (30.4\%) and 781/2452 (32\%) were hypertensive and diabetic patients, respectively. These findings show strong association between obesity and hypertension or diabetes, both showed statistically significant differences (hypertension $P<0.01$ and diabetes $P<0.001$ ), as indicated in Figure 3 .

In regard to the relationship between normal wt and hypertension or DM in different age ranges, it was observed that DM is increasing among older age ranges, hence, hypertension was observed more frequent among younger age ranges, as indicated in Figure 4.

\section{Discussion}

The prevalence of overweight and obesity was highest in the Americas (62\% for overweight in both sexes and 26\% for obesity) and lowest in South East Asia (14\% overweight in both sexes and 3\% for obesity) [18]. 


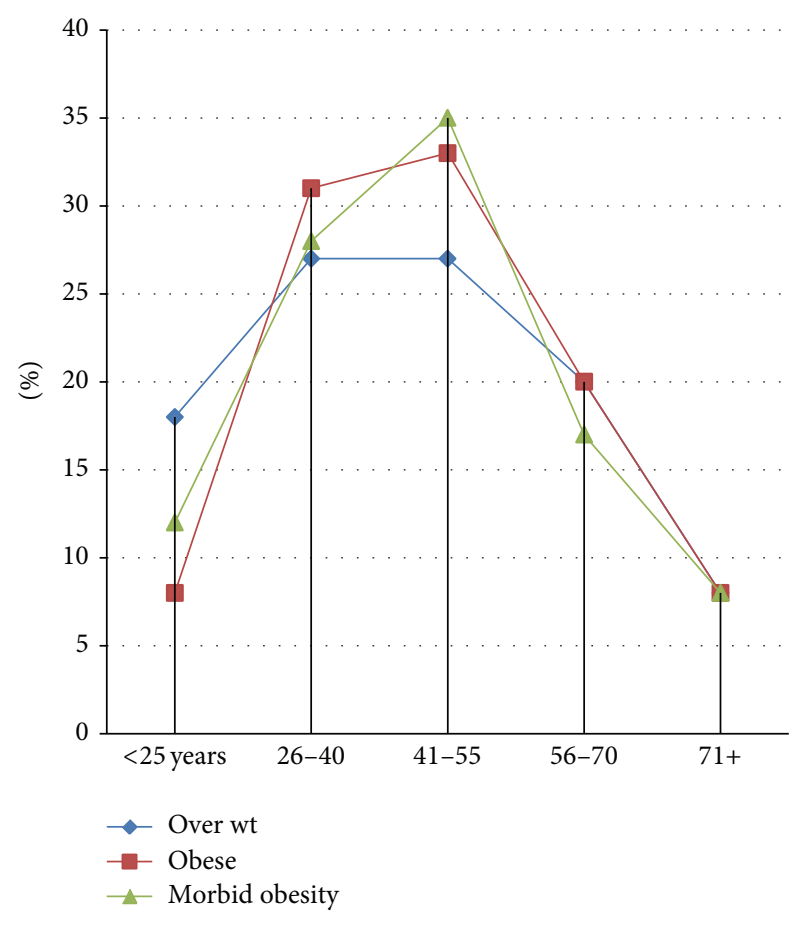

FIGURE 2: Description of the proportions of obesity categories by age ranges.

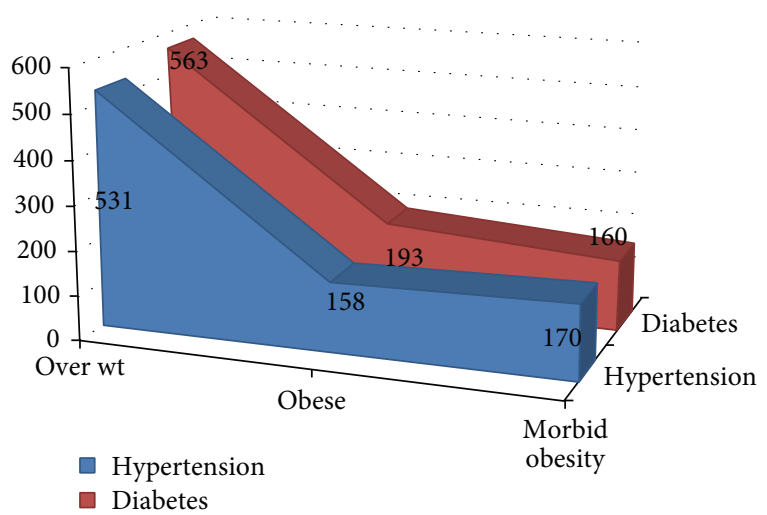

FIgURE 3: Description of obesity by hypertension and diabetes.

The increased consumption of fast foods and sugardense beverages (e.g., sodas) as well as the extensive use of cars, elevators, escalators, and remotes in recent years has dramatically increased the burden of obesity in KSA. Thus the increased prevalence rate of obesity in the present study indicates the magnitude of the problem in relation to daily life-style.

According to Forbes, Saudi Arabia ranks 29 on a 2007 list of the fattest countries with a percentage of $63.5 \%$ of its citizens being overweight (BMI > 25) [19], which is similar to our findings in this study (63.6\%). However, some studies from Saudi Arabia have showed lower prevalence rates than

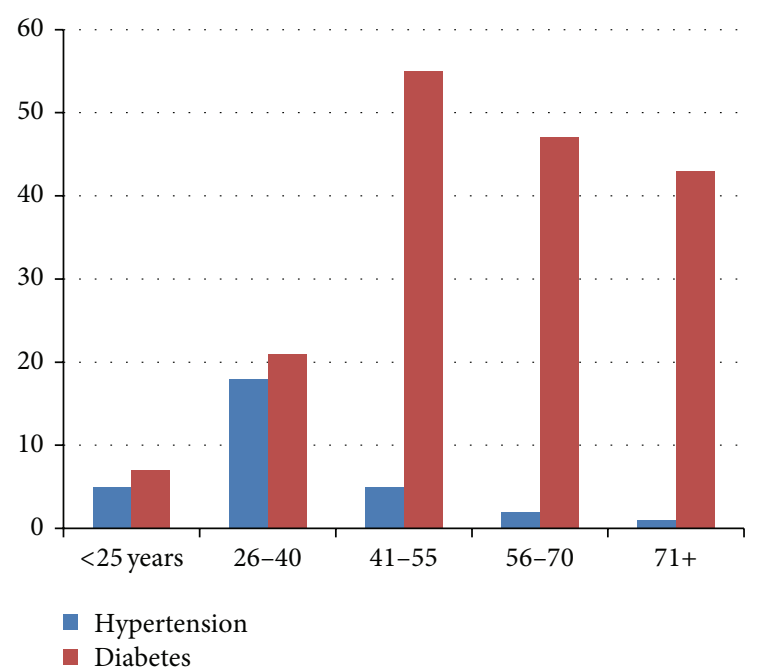

FIGURE 4: Description of the normal wt by hypertension and diabetes and by different age ranges.

Forbes report and our findings in the current study. According to epidemiological studies and surveys, obesity was found to affect more than one quarter while overweight affects about one-third of adults in Saudi Arabia [20-23]. Four studies that were conducted among four different age groups in Saudi Arabia revealed the following findings. Overweight among adult males and females was (30.7\% and $28.4 \%$, resp.), while obesity among adult males and females were $(14 \%$ and $23.6 \%$, resp.) [21]. The prevalence of overweight among adults population was $36 \%$ and the prevalence of obesity among the adult population was $35.6 \%$ [20]. Prevalence of overweight and obesity among children and adolescents $5-18$ years was $23.1 \%$ and $11.3 \%$, respectively [24]. Prevalence of overweight and obesity among females of childbearing age was 31.5\% and $21 \%$, respectively [25]. The prevalence of overweight and obesity among college students were $21.8 \%$ and $15.7 \%$, respectively [26]. Data regarding these studies were collected many years before and since there is a global fast increase in obesity and in KSA in particular, the elevated increase in the prevalence rates is expected due to strong dependent on factors that increase the risk of obesity among Saudi civilians.

In a study that involved a cross-sectional survey of 2,250 Saudi male soldiers aged between 20 and 60 years residing in a military city in northern Saudi Arabia conducted in 2004, over $82 \%$ of the subjects were either overweight or obese [27]. In a study (2009-2011) to measure the prevalence of obesity among military personnel in KSA, it was reported that $40.9 \%$ of the participants were overweight, $29 \%$ obese, and $42.4 \%$ had central obesity [28].

In a study form Saudi Arabia, the percent of different categories of body composition in healthy Saudi adults and its relationship with fitness scoring. The percent of the prevalence of underweight, normal weight, overweight, obesity class I, obesity class II, and obesity class III was $2.91(n=$ 13), $33.81(n=139), 35.27(n=145), 19.46(n=80), 6.32$ 
$(n=26)$, and $2.18(n=9)$, in this order. The study concluded that the prevalence of obesity, percent body fat, and poor fitness was high in the study population with significant gender differences. Public awareness programmes, including exercise and diet habits change, are necessary at mass scale to cope with the growing burden of obesity [29].

However, increased rates of obesity in Hail region over the other parts of Saudi Arabia are previously reported, as the prevalence of obesity ranged from $33.9 \%$ in Hail to $11.7 \%$ in Jizan [21]. Dietary behaviors varied across gender and BMI groups, with males preferring dining out, eating fast foods, and carbonated beverages as compared to females who preferred dining with family, snacking on potato chips, chocolates, cakes, sweets, and drank more caffeinated beverages. Both genders were at risk for dietary behaviors like eating less fruits and vegetables. Snacking was inversely associated with overweight and obesity $(P=0.05)$ while drinking caffeinated beverages was positively linked $(P=$ 0.043). Skipping breakfast $(P=0.006)$, low consumption of fruits $(P=0.012)$, and frequent restaurant visits $(P=0.027)$ were significantly associated with prevalence of high BMI\% [30].

In this study, increased weight categories were strongly linked to females and this was found to be statistically significant $(P<0.0001)$. In all WHO regions, women were more likely to be obese than men. In the WHO regions for Africa, Eastern Mediterranean, and South East Asia, women had roughly doubled the obesity prevalence of men [18]. Moreover, many studies from KSA indicated that the prevalence of obesity among females was significantly higher than for males [30-32].

The results of the current study showed a strong association between obesity and hypertension or diabetes, which showed a statistically significant difference (hypertension $P<0.01$ and diabetes $P<0.001$ ), when compared to nonhypertensives or nondiabetics. The relationship between obesity and hypertension or/and diabetes is well established in several studies [33,34]. In a study from KSA to assess the effect of overweight and obesity on diabetes and hypertension, the prevalence of obesity among diabetics and hypertensive patients was $46 \%$ and $54 \%$, respectively [35].

In conclusion, overweight and obesity are prevalent in Hail, KSA, and should be considered a serious public health problem. The prevalence is increasing, which necessitates urgent interventions. Practicable solutions include health education regarding the right food choices and encouraging physical exercise among all age groups for both genders.

\section{Conflict of Interests}

The authors declare that there is no conflict of interests regarding the publication of this paper.

\section{Acknowledgments}

The authors would like to express their special appreciation and thanks to his Excellency Professor (Dr.) Nasir Alrasheed for funding this project. The authors appreciate the assistance from the medical college's staff and medical students (University of Hail), health authority in Hail, the Saudi community leaders, and participants. This work was supported by grants from his Excellency Professor Dr. Nasser Elrasheed Chair for Renal Diseases Research.

\section{References}

[1] WHO Media Centre, Obesity and Overweight, World Health Organization, Geneva, Switzerland, 2013, http://www.who.int/ mediacentre/factsheets/fs311/en/.

[2] WHO, "Obesity: preventing and managing the global epidemic. Report of a WHO consultation," World Health Organization Technical Report Series 894:i-xii, 2000.

[3] B. Caballero, “The global epidemic of obesity: an overview," Epidemiologic Reviews, vol. 29, no. 1, pp. 1-5, 2007.

[4] P. T. James, R. Leach, E. Kalamara, and M. Shayeghi, "The worldwide obesity epidemic," Obesity Research, vol. 9, no. 4, pp. 228S233S, 2001.

[5] T. Kelly, W. Yang, C.-. Chen, K. Reynolds, and J. He, "Global burden of obesity in 2005 and projections to 2030," International Journal of Obesity, vol. 32, no. 9, pp. 1431-1437, 2008.

[6] J. Sobal and A. J. Stunkard, "Socioeconomic status and obesity: a review of the literature," Psychological Bulletin, vol. 105, no. 2, pp. 260-275, 1989.

[7] C. A. Monteiro, E. C. Moura, W. L. Conde, B. Popkin, and M. Barry, "Socioeconomic status and obesity in adult populations of developing countries: a review," Bulletin of the World Health Organization, vol. 82, no. 12, pp. 940-946, 2004.

[8] L. McLaren, "Socioeconomic status and obesity," Epidemiologic Reviews, vol. 29, no. 1, pp. 29-48, 2007.

[9] P. Clarke, P. M. O’Malley, L. D. Johnston, and J. E. Schulenberg, "Social disparities in BMI trajectories across adulthood by gender, race/ ethnicity and lifetime socio-economic position: 1986-2004," International Journal of Epidemiology, vol. 38, no. 2, pp. 499-509, 2009.

[10] WHO, Obesity and Overweight, World Health Organization, April 2009.

[11] D. C. W. Lau, J. D. Douketis, K. M. Morrison, I. M. Hramiak, A. M. Sharma, and E. Ur, "2006 Canadian clinical practice guidelines on the management and prevention of obesity in adults and children [summary]," Canadian Medical Association journal, vol. 176, no. 8, pp. S1-S13, 2007.

[12] L. A. Barness, J. M. Opitz, and E. Gilbert-Barness, "Obesity: genetic, molecular, and environmental aspects," American Journal of Medical Genetics A, vol. 143, no. 24, pp. 3016-3034, 2007.

[13] S. Bleich, D. Cutler, C. Murray, and A. Adams, "Why is the developed world obese?" Annual Review of Public Health, vol. 29, pp. 273-295, 2008.

[14] A. Drewnowski and S. E. Specter, "Poverty and obesity: the role of energy density and energy costs," American Journal of Clinical Nutrition, vol. 79, no. 1, pp. 6-16, 2004.

[15] M. Nestle and M. F. Jacobson, "Halting the obesity epidemic: a public policy approach," Public Health Reports, vol. 115, no. 1, pp. 12-24, 2000.

[16] W. P. James, "The fundamental drivers of the obesity epidemic," Obesity Reviews, vol. 9, no. 1, pp. 6-13, 2008.

[17] WHO Expert Consultation, "Appropriate body-mass index for Asian populations and its implications for policy and intervention strategies," The Lancet, vol. 363, no. 9403, pp. 157-163, 2004. 
[18] Global Health Observatory (GHO), Obesity: Situation and Trends, World, 2013, http://www.who.int/gho/ncd/risk_factors/ obesity_text/en/.

[19] L. Streib, "World's Fattest Countries," 2009-2012, http://www .forbes.com/2007/02/07/worlds-fattest-countries-forbeslifecx_ls_0208worldfat.html.

[20] M. M. Al-Nozha, Y. Y. Al-Mazrou, M. A. Al-Maatouq et al., "Obesity in Saudi Arabia," Saudi Medical Journal, vol. 26, no. 5, pp. 824-829, 2005.

[21] A. I. Al-Othaimeen, M. Al-Nozha, and A. K. Osman, "Obesity: an emerging problem in Saudi Arabia. Analysis of data from the national nutrition survey," Eastern Mediterranean Health Journal, vol. 13, no. 2, pp. 441-448, 2007.

[22] N. M. Al-Daghri, O. S. Al-Attas, M. S. Alokail et al., "Diabetes mellitus type 2 and other chronic non-communicable diseases in the central region, Saudi Arabia (riyadh cohort 2): a decade of an epidemic," BMC Medicine, vol. 9, article 76, 2011.

[23] I. E. Barrimah, A. R. Mohaimeed, F. Midhat, and H. A. AlShobili, "Prevalence of metabolic syndrome among Qassim university personnel in Saudi Arabia," International Journal of Health Sciences, vol. 3, pp. 133-142, 2009.

[24] M. I. El Mouzan, P. J. Foster, A. S. Al Herbish et al., "Prevalence of overweight and obesity in Saudi children and adolescents," Annals of Saudi Medicine, vol. 30, pp. 203-208, 2010.

[25] J. S. Al-Malki, M. H. Al-Jaser, and A. S. Warsy, "Overweight and obesity in Saudi females of childbearing age," International Journal of Obesity and Related Metabolic Disorders, vol. 27, no. 1, pp. 134-139, 2003.

[26] A. S. Al-Rethaiaa, A. A. Fahmy, and N. M. Al-Shwaiyat, "Obesity and eating habits among college students in Saudi Arabia: a cross sectional study," Nutrition Journal, vol. 9, no. 1, article 39, 2010.

[27] D. A. Al-Qahtani, M. L. Imtiaz, and M. M. Shareef, "Obesity and cardiovascular risk factors in Saudi adult soldiers," Saudi Medical Journal, vol. 26, no. 8, pp. 1260-1268, 2005.

[28] G. B. Horaib, H. I. Al-Khashan, A. M. Mishriky et al., "Prevalence of obesity among military personnel in Saudi Arabia and associated risk factors," Saudi Medical Journal, vol. 34, no. 4, pp. 401-407, 2013.

[29] SS. Habib, "Body composition analysis and estimation of physical fitness by scoring grades in Saudi adults," Journal of the Pakistan Medical Association, vol. 63, no. 10, pp. 1285-1289, 2013.

[30] M. A. Faris, S. Epuru, D. Abu-Jamous, M. Smadi, A. Eideh, and E. Alshammari, "Assessing obesity, body fatness and dietary behaviors among adult college students in Hail, Saudi Arabia," International Journal of Nutrition and Food Sciences, vol. 3, no. 2, pp. 60-68, 2014.

[31] A. R. Al-Nuaim, K. Al-Rubeaan, Y. Al-Mazrou, O. Al-Attas, N. Al-Daghari, and T. Khoja, "High prevalence of overweight and obesity in Saudi Arabia," International Journal of Obesity and Related Metabolic Disorders, vol. 20, no. 6, pp. 547-552, 1996.

[32] M. Badran and I. Laher, "Obesity in Arabic-speaking countries," Journal of Obesity, vol. 2011, Article ID 686430, 9 pages, 2011.

[33] M. N. Stagnitti, "Trends in Health Care Expenditures by Body Mass Index (BMI) Category for Adults in the U.S. Civilian Noninstitutionalized Population, 2001 and 2006," Statistical Brief, vol. 247, pp. 1-7, 2009.

[34] M. T. Zanella, O. Kohlmann Jr., and A. B. Ribeiro, "Obesity- and diabetes-related hypertension: treatment of obesity hypertension and diabetes syndrome," Hypertension, vol. 38, no. 3, pp. 705-708, 2001.
[35] A. M. AL-Shahrani and Y. M. Al-Khaldi, "Obesity among diabetic and hypertensive patients in Aseer region, Saudi Arabia," Saudi Journal of Obesity, vol. 1, pp. 14-17, 2013. 


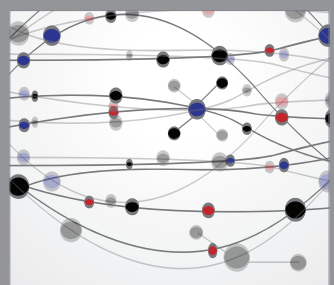

The Scientific World Journal
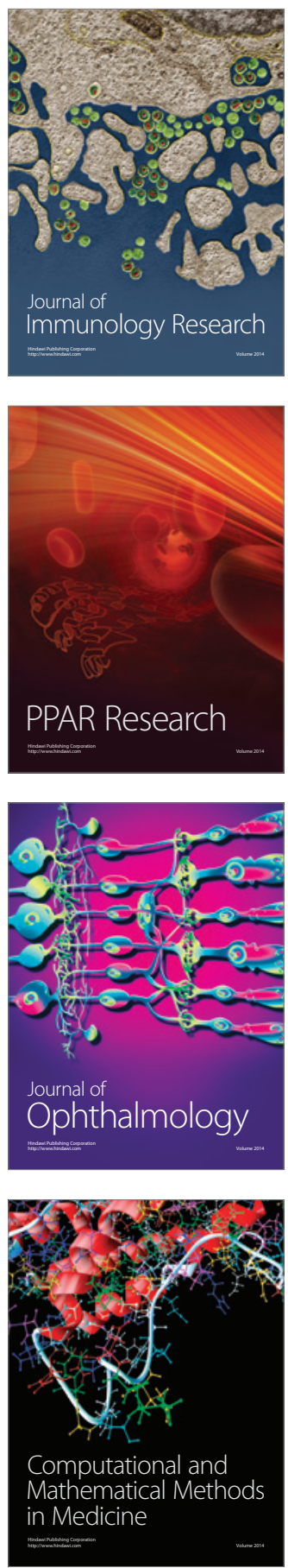

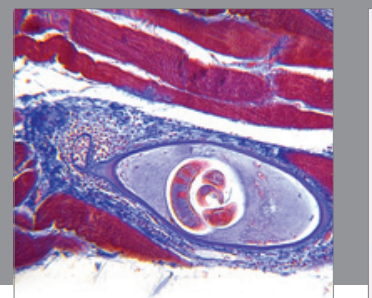

Gastroenterology

Research and Practice
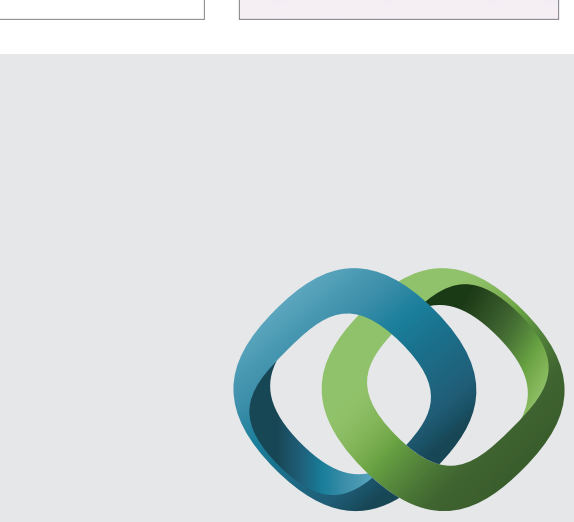

\section{Hindawi}

Submit your manuscripts at

http://www.hindawi.com
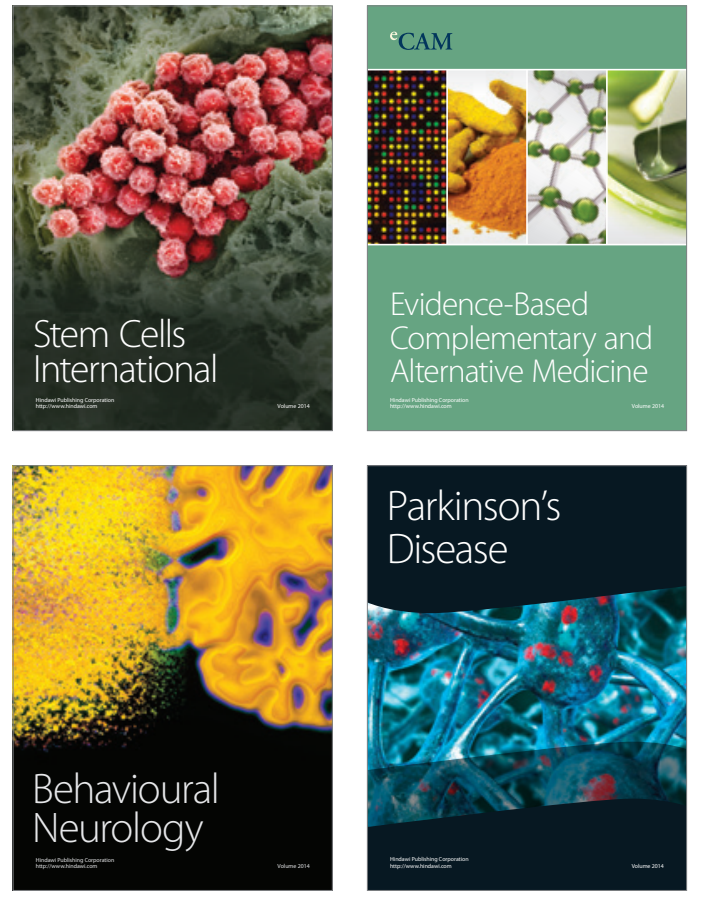
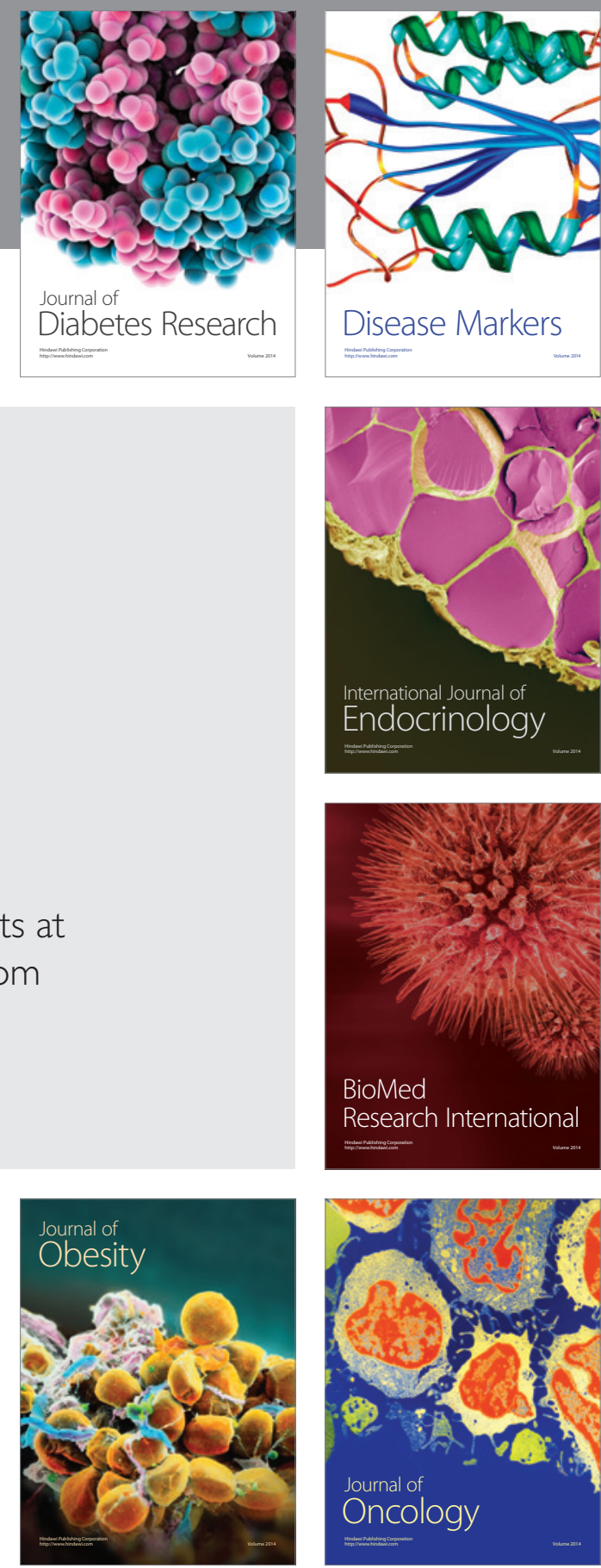

Disease Markers
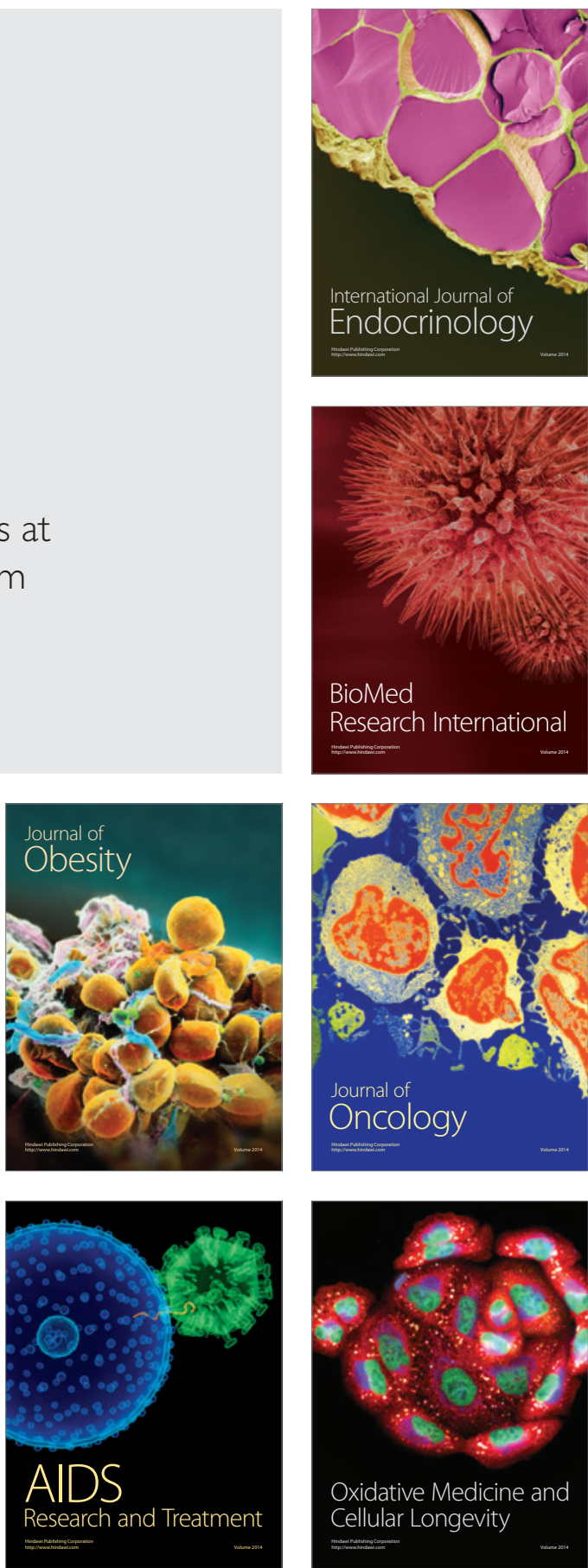